\title{
Surdos e Homossexuais: A (Des)coberta de Trajetórias Silenciadas
}

\author{
Fabrício Santos Dias de Abreu ${ }^{1}$ \\ Secretaria de Estado de Educação do Distrito Federal, Brasília, DF, Brasil \\ Programa de Pós-Graduação em Processos de Desenvolvimento Humano e Saúde \\ da Universidade de Brasília, Brasília, DF, Brasil \\ Grupo de Pesquisa Pensamento e Cultura e Grupo de Estudo em Ecologia Sexual e Educação \\ da Universidade de Brasília, Brasília, DF, Brasil \\ Daniele Nunes Henrique Silva \\ Programa de Pós-Graduação em Processos de Desenvolvimento Humano e Saúde \\ e Departamento de Psicologia Escolar e Desenvolvimento da Universidade de Brasília, \\ Brasilia, DF, Brasil \\ Grupo de Pesquisa Pensamento e Linguagem da Universidade Estadual de Campinas, \\ Campinas, SP, Brasil \\ Vice-Líder do Grupo de Pesquisa Pensamento e Cultura da Universidade de Brasília, \\ Brasilia, DF, Brasil \\ José Zuchiwschi \\ Departamento de Teoria e Fundamentos da Faculdade de Educação da Universidade \\ de Brasília, Brasília, DF, Brasil \\ Lider do Grupo de Estudo em Ecologia Sexual e Educação da Universidade de Brasília, \\ Brasília, DF, Brasil
}

\section{Resumo}

Os estudos sobre a expressão da sexualidade das pessoas surdas são diminutos e muitas vezes não problematizam assuntos voltados às orientações afetivo-sexuais destoantes do padrão heteronormativo. A fim de preencher a carência de pesquisas nessa área, o presente trabalho investiga as narrativas de sujeitos surdos sobre as suas primeiras experiências homossexuais e o enfrentamento do duplo preconceito; ser surdo e homossexual. Esta pesquisa se insere em uma abordagem qualitativa, tendo como instrumento metodológico a condução de entrevistas semiestruturadas. Os dados revelam que a condição homossexual entre os surdos ainda é pouco compreendida, pois há dúvidas, preconceitos e mitos acerca das experiências afetivo-eróticas. Além disso, as narrativas dos entrevistados evidenciam que a primeira relação sexual com pares de mesmo sexo, ocorrida em um ambiente próximo e relacional (doméstico e escolar) sem a anuência dos mesmos, é um marco que desencadeia os processos de constituição da sexualidade. Tais questões apontam para a necessidade de ampliação de investigações que considerem as relações entre emoção, linguagem e constituição da identidade sexual. Para além, sugere uma atenção

Endereço para correspondência: Universidade de Brasília, Instituto de Psicologia, Campus Universitário Darcy Ribeiro, Asa Norte, Brasília, DF, Brasil 70910-900. E-mail: fabra201@hotmail.com, daninunes74@gmail. com e josez@terra.com.br

Partes das discussões suscitadas no manuscrito fazem parte das reflexões oriundas do Grupo de Trabalho em Desenvolvimento Humano e Narrativas de Formação apresentadas na Associação Nacional de Pesquisa e PósGraduação em Psicologia (ANPEPP/2012), no qual a segunda autora é membro.

A pesquisa contou com o apoio financeiro do Conselho Nacional de Desenvolvimento Científico e Tecnológico (CNPq) e da Fundação de Empreendimentos Científicos e Tecnológicos (Finatec). 
especial para os surdos, em razão de suas especificidades linguísticas e da sua vulnerabilidade social, bem como a necessidade de desenvolvimento de políticas públicas voltadas para esse grupo.

Palavras-chave: Surdez, homossexualidade, narrativa, preconceito.

\title{
Deaf and Homosexuals: The Discovery of Silenced Trajectories
}

\begin{abstract}
The studies on the expression of deaf people sexuality are scarce (rare) and usually they do not emphasize the issues concerning the sexual and love attachment out of the heteronormative main stream. In order to fill the lack of research in this area, the present article investigates the deaf people narratives on their primary homosexual experiences and their strugle against the double prejudice: on being deaf and homosexual. This research is part of a qualitative approach, having as methodological instrument the semi-structured interviews. The data reveal that the homosexual condition of the deaf people is still little understood on account of many doubts, prejudices and myths about their sexual and emotional attachment experiences. Moreover, the narratives of the interviewees showed that their first same sexual relation, without their consent, occurred into their familiar and domestic environment (home and school), fact that becomes the essencial basis for the constitutional process of their further sexuality. These issues point to the need for an extension of the investigations considering the emotional aspects, language and the construction of sexual identity interface. In addition, it suggests a special attention for the deaf people, due to their specific language characteristics and their social vulnerability, as well as the need for the development of effective public policies for this social group.
\end{abstract}

Keywords: Deafness, homosexuality, narrative, prejudice.

\section{Sordos y los Homosexuales: El Descubrimiento de las Trayectorias Silenciadas}

\section{Resumen}

Los estudios sobre la sexualidad de las personas sordas son reducidos y no problematizan aquellas que posuem orientaciones afectivas y sexuales divergentes de la norma heteronormativa. Buscando abordar la falta de investigación en esta área, este trabajo investiga las narrativas de las personas sordas en sus primeras experiências homosexuales, enfatizando el doble prejuicio; ser sordo y gay. Esta investigación es parte de un enfoque cualitativo,con entrevistas semi estructuradas. Los datos revelan que la condición homosexual entre los sordos aún es poco conocido, ya que hay dudas, prejuicios y mitos acerca de las experiencias afectivas y eróticas. Los participantes indican que su primera relación sexual con parejas del mismo sexo, que tuvo lugar en el entorno cercano y relacional (hogar y escuela) sin el consentimiento de la misma, es un hito que desencadena los procesos de formación de la sexualidad. Estas cuestiones apuntan a la necesidad de ampliar las investigaciones que tengan en cuenta la relación entre la emoción, el lenguaje y la constitución de la identidad sexual. Además, sugiere una especial atención a los sordos, debido a sus especificidades lingüísticas y vulnerabilidad social, y la necesidad de desarrollo de políticas públicaspara este grupo cultural.

Palabras clave: Sordera, homosexualidad, narrativa, preconcepto.

Os estudos acerca das vivências da sexualidade de pessoas com desenvolvimento atípico são escassos e raramente investigam assuntos voltados à orientação afetivo-sexual desses sujeitos, principalmente, as manifestações que estão fora da ordem heteronormativa (Abreu \& Silva, 2012). De fato, a expressão da homossexualidade em pessoas com deficiência, por 
exemplo, tem sido pouco problematizada na literatura cientifica especializada, principalmente, em âmbito nacional. Essa situação não deixa de ser uma repetição, no universo acadêmico, da marginalização que acontece mundialmente na esfera social e econômica (Bisol, 2008).

De acordo com Vigotski (1997), aqueles considerados deficientes, por se desenvolverem a partir de padrões não convencionais, são concebidos culturalmente como sujeitos incapazes de viver amplamente em sociedade. Aliada às limitações sociais impostas a essas pessoas, a expressão da sexualidade é uma temática pouco problematizada, pois prevalece a ideia de que os sujeitos com desenvolvimento atípico são infantis e inocentes (incompletos pelo déficit orgânico) e sem uma dinâmica afetivo-sexual (Maia, 2006, 2010; Maia \& Ribeiro, 2010; Paula, Regen, \& Lopes, 2005; K. Ribeiro, 2011; Sànchez, 2013; entre outros).

Apesar de a bibliografia científica recente contestar a relação entre deficiências e problemática/limitação sexual como sinônimos (Beche, 2005; Bisol, 2008; Maia, 2006; Moukarzel, 2003; entre outros), prevalece a noção de que a sexualidade ora inexiste, ora é deformada, assim como a pessoa que a expressa. $\mathrm{O}$ que predomina nos discursos cotidianos a respeito da sexualidade de pessoas com deficiência é que ela se manifesta de forma atípica, infeliz (quase patológica), sem expectativa de união afetivo-sexual, sendo narrada de forma trágica e platônica que tende a se realizar de forma desajustada.

A relação entre homossexualidade e deficiência anuncia discussões teóricas importantes sobre desenvolvimento e sexualidade. Estudos realizados por Maia (2009a, 2009b, 2010) e Maia e Ribeiro (2010) e revelam o caráter inédito da temática, abrindo vias, no contexto brasileiro, para investigações sobre a formação da pessoa deficiente, também, homossexual. Ou seja, sujeitos que se constituem a partir de duas (ou mais) características pessoais que são socialmente construídas em um espaço de menor valia, e, portanto, consideradas desvantajosas.

No atual contexto de organização social existem estratégias de desqualificação e normatização para todos aqueles considerados des- viantes dos padrões estabelecidos pela sociedade capitalista hegemônica (Bauman, 1998). Nessa configuração, nota-se a existência de subalternidades de categorias de diferenciação, síntese da junção de vários eixos de exclusão e exploração social. Essa situação se agrava quando articulada às práticas ideológicas e institucionais que privilegiam uma classe burguesa, masculina, branca, ocidentalizada e sem deficiência. Afinal, é para eles e por meio deles que os direitos são constituídos.

Estudos, com maior ou menor ênfase, têm discutido essas sobreposições de exclusão e seu impacto na constituição da pessoa, mostrando que a vida de sujeitos situados fora do padrão se configura em diversos contextos de desigualdade social; estruturados por meio de repressão, subalternização e opressão cotidiana. Pesquisa com surdos negros (Buzar, 2012), surdos homossexuais (Abreu \& Silva, 2012; Silva, 2011) e mulheres surdas (Costa, 2011; Moreira, 2008) compõem esse interessante eixo investigativo, indicando que a condição de deficiência, em consonância com outro marcador social marginalizante, costura, dramaticamente, a subjetividade.

Percebe-se que a deficiência, muitas vezes, é tomada como característica principal do sujeito, não podendo coexistir atitudes e desejos que fujam da normalidade imposta como regra. Desconsidera-se que frente à condição da deficiência, amalgamam-se outros estigmas e preconceitos como: a questão de gênero, orientação sexual, raça, classe, etc.

A própria negação de que as pessoas com deficiência possam ter desejos de ordem homossexual reflete a invisibilidade da sua sexualidade. Se entendermos que essas pessoas são sexuadas como as demais, considerando que a sexualidade é uma característica humana independente da condição de deficiência, também assumimos que elas podem expressar desejos e afetos que fujam dos padrões hegemônicos. Porém, é muito incomum nos estudos da área de educação especial e inclusiva (ou até mesmo nos de diversidade sexual) a referência a pessoas deficientes como sendo gays, lésbicas, transexuais, etc. Salientamos, contudo, que tal temática já tem sido de- 
batida em algumas obras cinematográficas, tais como: A Prova (House \& Moorhouse, 1991); Tudo em Família (London \& Bezucha, 2005); Hoje Eu Quero Voltar Sozinho (D. Ribeiro, 2014) e em obras literárias internacionais: Amago, 2005; Luczak, 1993, 2013.

\section{Identidades Sexuais e de Gênero na Contemporaneidade}

Atualmente, as questões relacionadas à sexualidade estão sendo pautadas em diversas áreas do conhecimento, tais como psicologia, educação, antropologia social e saúde pública. Tanto no campo acadêmico quanto nos espaços institucionais e sociais, esse tema faz parte da agenda cultural, no que se refere, principalmente, às novas configurações de modelo familiar $\mathrm{e}$ às relações afetivo-sexuais que transgridem as fronteiras estabelecidas como convencionais.

Para Madureira (2000), as identidades de gênero (as múltiplas formas de tornar-se homem ou mulher) e as identidades sexuais (as variadas configurações como são subjetivadas as orientações sexuais), apesar de serem conceitos distintos, apresentam interdependência coconstitutiva. Tais identidades, além de funcionarem como aportes culturais no processo de constituição da subjetividade, posicionam os sujeitos em suas relações com os diversos grupos sociais existentes no contexto cultural em que estão inseridos. As identidades sexuais e de gênero se inter-relacionam e estão sempre em constituição, sendo passíveis de transformação ao longo do desenvolvimento ontogênico, reconfigurando-se a partir das experiências vivenciadas por cada pessoa.

De fato, a ideia de permanência e unidade identitária encontra-se frequentemente presa a uma visão inata, natural, biológica e hereditária da sexualidade, descontextualizada dos parâmetros culturais, políticos e históricos que configuram as experiências sexuais, afetivas e eróticas da contemporaneidade.

Sobre isso, afirma Britzman (1996):

Nenhuma identidade sexual - mesmo a mais normativa - é automática, autêntica, facilmente assumida; nenhuma identidade sexu- al existe sem negociação ou construção. . . . Toda identidade sexual é um constructo instável, mutável e volátil, uma relação social contraditória e não finalizada. (p. 74)

Segundo Weeks (2007), a sexualidade está relacionada com as nossas crenças, ideologias, desejos, prazer, imaginação, entre outros, bem como com nosso corpo físico e simbólico. Ela está, portanto, articulada a um determinado constructo social. Esse constructo é uma invenção histórica, tendo como base as possibilidades do corpo. Nessa linha, Foucault (2006) afirma que "a sexualidade é o nome que se pode dar a um dispositivo histórico" (p. 100).

Não é possível fixar um momento dentro do processo de desenvolvimento humano (seja esse o nascimento, a adolescência ou a maturidade) como marco para o estabelecimento ou a internalização da identidade sexual e/ou de gênero (Louro, 1997). Como dito anteriormente, essas identidades são negociadas e não estão predeterminadas por um momento específico da trajetória ontogênica.

Segundo Madureira (2000), ainda hoje há uma tendência de procurar marcas genéticas, de ordem físico-biológica, para as manifestações sexuais, como a homossexualidade, por exemplo. No entanto, “. . . somos seres que podem atravessar as fronteiras discursivo-culturais da sexualidade e se familiarizar com outros discursos sobre quem podemos ser sexualmente" (Lopes, 2008, p. 138).

Os termos homossexualidade e heterossexualidade, conceitual e linguisticamente, são relativamente novos, marcados pelo pensamento moderno e contemporâneo. De acordo com Weeks (2007), até meados do século XIX, a atividade sexual entre pessoas do mesmo sexo biológico era tratada sob a categoria geral e mal definida da sodomia.

Os sodomitas seriam pessoas que apresentavam um potencial de natureza pecadora e transitória, e não uma atividade própria de um tipo específico de pessoas. Essa era uma categoria bastante ampla, que incluía contatos sexuais (não necessariamente anais) de homens com homens ou com animais. Em suma, tratava-se de 
relações que desafiavam a reprodução. $\mathrm{O}$ que definia a sodomia eram os comportamentos e não as inclinações afetivas e sexuais. Assim, o indivíduo que tivesse o desejo de praticá-la, mas não o fizesse, não era considerado um desviante. Aquele que, por sua vez, abandonasse o vício deixava de ser sodomita. A sodomia se definia pela pelo ato, e não pela pessoa (Nunan, 2003).

De pecado a crime, as relações afetivo-sexuais entre pessoas do mesmo sexo passaram, a partir do surgimento do conceito de homossexualidade cunhado por Karl Kertbeny, em 1869, a ser considerada doença e desvio; passíveis de tratamento e normatização (Borrillo, 2010; Madureira, 2000). Elas foram inseridas, assim, no discurso médico e patológico. Em tese, o sodomita deixava de existir para dar lugar ao homossexual, que se transformava em uma espécie de pessoa. Conforme argumenta Foucault:

A homossexualidade apareceu como uma das figuras da sexualidade quando foi transferida, da prática de sodomia, para uma espécie de androgenia interior, um hermafroditismo da alma. O sodomita era um reincidente, agora o homossexual é uma espécie (2006, pp. 50-51).

O homossexual não era mais um sujeito qualquer que tinha caído em pecado, mas um sujeito de outra natureza. Para esse tipo de sujeito, haveria de ser inventada e posta em prática uma sequência de ações visando à reintegração ao padrão de normalidade. Porém, ainda que se afirmasse a primazia da heterossexualidade, observa-se que ela apenas se constitui como "sexualidade-referência" depois da instituição da homossexualidade (Louro, 2009, p. 89).

No fim do século XIX e início do século XX, os termos passaram a definir mais estreitamente os tipos de comportamento sexual e as identidades sexuais. A homossexualidade foi assumida como um discurso médico-moral e a heterossexualidade ficou estabelecida como descrição da norma, ocorrendo uma dualidade opositora entre os termos e uma valorização de um sobre o outro. Assim, institucionalizou-se a heterossexualidade, produzindo uma hierarquia na qual o anormal e o normal passaram a ser distinguidos e hierarquizados.
Madureira (2000) argumenta que, antes do século XIX, as preocupações com a sexualidade estavam ligadas à religião ou à filosofia moral. Com o surgimento da sexologia, a sexualidade passou a ser objeto de estudo científico, o que deu início a um esforço classificatório para cunhar categorias.

A medicina, na virada do século XIX para o $\mathrm{XX}$, propunha ações médico-corretivas para os homossexuais, e a homossexualidade passou a ser compreendida em termos biológicos. A medicina assumiu para si, apoiada em um discurso da Igreja Católica, a obrigação de conduzir o homem ao caminho correto da sexualidade, em que o sexo era justificado apenas para a reprodução da espécie e qualquer atividade sexual que se distanciasse desse preceito seria um pecado contra a natureza humana (Ferrari, 2005).

Goffman (1998) aponta que, com a normatização da identidade heterossexual, estabelece-se um processo constante de estigmatização das identidades homossexual e bissexual. Nesse processo, tais identidades passam a ser consideradas deterioradas, como se escondessem uma falha fundamental.

Para Louro (2009), ao se entender sexo como algo natural, imutável, a-histórico e binário, impõem-se limites à concepção de gênero e sexualidade, pois se equaciona a heterossexualidade como forma compulsória e normativa (heterossexismo). Assim, os sujeitos que escapam à heteronormatividade são colocados à margem das preocupações dos espaços institucionalizados e da sociedade em geral. Vivem a experiência de exclusão, compondo o quadro geral daqueles considerados estranhos (Bauman, 1998), fora da norma(lidade).

Assim, a sexualidade se manifesta em um contexto cultural e histórico. Cada sociedade estabelece conceitos de normalidade para comportamentos considerados adequados ou não, que devem ser incentivados ou reprimidos. Maia (2009b) esclarece que, da mesma forma como existem padrões de normalidade em relação à sexualidade, existem padrões culturais em relação ao desenvolvimento humano considerado saudável ou normal. Tais padrões culturais incluem expectativas voltadas ao desenvolvimento cog- 
nitivo, motor, linguístico etc., pautadas na ideia de perfeição, em que a deficiência é compreendida, por muitas pessoas, como um conjunto de diferenças desvantajosas.

\section{Delimitação do Estudo: A Homossexualidade e a Surdez como Desvio da Norma(lidade)}

É por meio do corpo que nos mostramos e nos relacionamos com o outro. Por ele, somos percebidos, aprovados ou reprovados. Porém, durante anos o corpo do sujeito deficiente foi (e tem sido) alvo de intervenções médicas, fisioterápicas e corretivas que não contribuem para despertar o erotismo. Ao contrário, tais intervenções apontam o que há de errado, diferente, que precisa ser consertado, normalizado; caso contrário, será um corpo doente (Paula et al., 2005).

Nesse contexto, o surdo é marcado pela sua incapacidade natural de audição. Seu corpo “... é representado e se institui como um órgão patológico [ênfase nosso] e esse corpo doente, deficiente, incapacitado, não deve ser pensado, celebrado, antes de sua normalização" (Moreira, 1998, p. 99).

Não ouvir é ser invisível, discriminado e excluído. Conforme salienta Skliar (2010), "ser ouvinte é ser falante e é também ser branco, homem, profissional, letrado, civilizado. Ser surdo, portanto, significa não falar - surdo mudo - e não ser humano" (p. 21).

Moreira (1998) aponta que os estudos realizados com surdos partem do eixo central do déficit linguístico (visão patológica), sendo a sexualidade tratada apenas como sinônimo de sexo, ato sexual, genitália ou reprodução de forma marginal, conforme discutiremos na análise dos dados.

Klein e Formozo (2007), por sua vez, afirmam que a combinação das categorias de gênero e surdez ainda é um assunto novo dentro das comunidades surdas, que têm como pauta maior a divulgação da Língua Brasileira de Sinais (Libras), o acesso à informação, a educação etc. São escassos, por exemplo, os espaços inclusivos para surdos (com uso da Libras) que bus- quem sanar dúvidas acerca da sexualidade e suas diversas manifestações. Nessa linha, segundo Anderson e Kitchin (2000), a maior dificuldade encontrada na vida de uma pessoa com deficiência, no que tange às questões da sexualidade, é causada pelo fracasso dos recursos educacionais (e de outros serviços) em oferecer-lhe esclarecimentos sobre o tema.

As pesquisas na área de sexualidade e surdez (Abreu \& Silva, 2012; Beche, 2005; Bisol, 2008; Lebedeff, 1993; K. Ribeiro, 2011; Silva, 2011), apesar do distanciamento temporal, parecem convergir no sentido de revelarem que: (a) há uma desigualdade na qualidade informativa do material pedagógico apresentado para ouvintes e surdos no ambiente escolar; (b) os conteúdos acerca da sexualidade são entendidos pelos surdos de forma deturpada, principalmente, pelas suas peculiaridades linguísticas, ocasionando acesso restrito aos bens culturais e as dinâmicas sociais; (c) a temática da homossexualidade é negligenciada, sendo problematizada de forma menor; e (d) os surdos homossexuais não encontram suporte afetivo, informativo e comunicativo nos ambientes educacionais e familiares para sanarem suas dúvidas e serem aceitos pela sua condição de expressão sexual. Desses estudos, apenas alguns (Abreu \& Silva, 2012; Silva, 2011) tem como foco investigativo as vivências homossexuais de sujeitos surdos.

Com o intuito de analisar como a família e os movimentos sociais contribuem para o processo educativo de surdos e surdas homossexuais, Silva (2011) partiu do Grupo de lésbicas, gays, bissexuais, travestis, transexuais e transgêneros (LGBT) Surdo, de Pernambuco, como lócus para a construção da sua pesquisa empírica. Por meio da observação dos encontros, o trabalho revelou que tais sujeitos eram guetificados nos ambientes escolares e familiares, encontrando na dinâmica grupal espaço propicio para sua formação humana e acadêmica.

Abreu e Silva (2012), por exemplo, detiveram-se às narrativas de surdos homossexuais adultos, alertando para as condições de vulnerabilidade social e sexual (violência física e simbólica) vivenciadas pelos entrevistados em suas primeiras experiências sexuais. 
As investigações apresentadas acima ${ }^{2}$ demarcam um espaço importante no campo investigativo que explora as expressões subjetivas minoritárias. Porém, torna-se importante refletir acerca da herança que se estabelece nos discursos de poder, vinculados aos ambientes sociais e culturais, que deslegitimam a construção de sexualidades destoantes dos padrões hegemônicos das pessoas surdas. Tais conclusões e apontamentos tencionam para a indagação: como sujeitos surdos homossexuais narram suas experiências sexuais? Ou ainda: como surdos homossexuais agenciam a experiência de enfretamento/ vivência do (duplo) preconceito?

\section{Metodologia ${ }^{3}$}

Este trabalho busca investigar as vivências socioculturais de surdos homossexuais, tendo como foco para construção dos dados empíricos a composição de narrativas pelos sujeitos pesquisados. Para tanto, visando um melhor alinhamento com os objetivos propostos, utilizamos como recurso metodológico entrevistas individuais semiestruturadas.

A opção por esse tipo de procedimento para a construção de dados visou potencializar um roteiro de entrevista mais flexível, em que o entrevistado é convidado a ter um papel ativo na interpretação das informações e o pesquisador (entrevistador) assume um papel menos diretivo. O pesquisador pode, assim, oferecer empatia e apoio, possibilitando um diálogo mais aberto e favorecendo a emergência de novos aspectos sig-

Além desses estudos, é importante destacar matérias vinculadas em revistas impressas e digitais que problematizam a surdez e a homossexualidade (principalmente aquelas atreladas à questão do duplo preconceito e da acessibilidade). A entrevista com Tomaz Beche (surdo e gay) no Portal G (09/02/2011) e a reportagem na Revista G Magazine intitulada: Licença pra Ouvir: Surdos Gays e Lésbicas Começam a se Organizar para Buscar seus Direitos, em 2004, são exemplos desses esforços.

3 A pesquisa aqui apresentada foi analisada e aprovada pelo Conselho de Ética em Pesquisa do Instituto de Ciências Humanas da Universidade de Brasília. nificativos (Souza, Branco, \& Lopes de Oliveira, 2008). Esse tipo de vínculo permite significar e ressignificar o vivido. Nela, o sujeito esforça-se, fazendo-se autor, para situar-se temporalmente e tecer a própria história, por meio da memória e de narrativas.

Assim, como sugere Duarte (2005), concordamos que o momento da entrevista se caracteriza pela troca, em que o pesquisador pode oferecer ao seu interlocutor a oportunidade de refletir sobre si mesmo, de refazer seu percurso biográfico, de pensar sobre sua cultura, seus valores, a história e as marcas que constituem o grupo social ao qual pertence. Assim, o espaço da entrevista consiste em um local dialógico, sendo perpassado pelos significados que são construídos pelos participantes (pesquisador/entrevistado).

\section{O Trabalho de Campo: A Construção dos Dados}

A seleção dos informantes desta pesquisa se caracterizou por ser do estilo conveniência, em que as fontes foram selecionadas pela proximidade, disponibilidade e aceitação em participar do estudo. Participaram da pesquisa três homens surdos de classe média da região Centro-Oeste do Brasil, na faixa etária entre 32 e 38 anos, que assumem uma identidade bilíngue (fazem uso da Língua de Sinais, como primeira língua, e do português, como segunda) e afirmam a homossexualidade como fator constitutivo de suas vivências eróticas e afetivas. São eles: ${ }^{4}$

- Mateus, 32 anos, branco: tem nível superior e é militante da comunidade surda;

- Lucas, 38 anos, branco: possui o curso de Magistério e é militante da comunidade surda;

- Artur, 37 anos, negro: estudou até o nível médio e é militante de um grupo LGBT.

Nas entrevistas, além do pesquisador, contou-se com a participação de uma intérprete fluente em Libras, já conhecida e aprovada pelos sujeitos entrevistados. Posteriormente à realização das entrevistas, elas foram transcritas

4 Os nomes dos sujeitos foram trocados, visando resguardar suas identidades. 
na íntegra para análise e categorização pelo próprio pesquisador. A transcrição visou garantir a fidelidade e o caráter confidencial do material coletado.

$\mathrm{Na}$ pesquisa qualitativa, a interpretação da entrevista requer do pesquisador uma atitude mais flexível em relação à categorização das respostas construídas pelo entrevistado. Isso vai de encontro com a pesquisa positivista, em que as categorias devem ser fechadas e previamente definidas (Madureira \& Branco, 2001). Para a discussão dos objetivos propostos neste trabalho, as transcrições foram estudadas por meio do detalhamento interpretativo das entrevistas. Nessa fase, compomos eixos de análise destacados em dois elementos centrais considerados relevantes para a exploração da problemática suscitada:

- Primeiras incursões de ordem sexual; e,

- Estratégias de enfrentamento do duplo preconceito.

Como poderá ser visto, essas problemáticas emergem na produção de discursos sinalizados pelos sujeitos, que serão discutidos e analisados a seguir.

\section{Unidade de Análise 1: Relatos Sobre as Primeiras Experiências Sexuais}

No início de cada entrevista, o pesquisador apresentava os objetivos da investigação e oferecia uma breve problematização acerca do tema. Logo em seguida, eram feitas perguntas aos sujeitos pesquisados que não tinham necessariamente relação direta com o tema da surdez e homossexualidade. A intenção era de propiciar um espaço para o despertar da narrativa; tratava-se de um modo de o sujeito começar a falar de si, de uma forma mais geral, para, em seguida, poder narrar aspectos mais íntimos de sua vida. Contudo, os sujeitos pesquisados, mesmo diante de perguntas mais amplas e pouco específicas, ignoravam a condução do pesquisador e imediatamente contavam suas vivências sexuais, como pode ser observado nos fragmentos discursivos de Lucas e Artur:

Pesquisador: "Durante a sua formação, principalmente na escola, esse tema, a questão da sexualidade, ela foi apresentada a você? Esse tema foi trabalhado durante a sua formação escolar?"

Lucas: Quando eu era criança, eu tinha um primo que ficava junto comigo e que acabou tendo relação sexual comigo e eu fui criado junto com ele, mas eu não entendia nada daquilo e desde criança esse meu primo tinha relação sexual comigo. Eu fui entendendo... . . . Eu gostei da relação homossexual, então, eu também tinha relação com ele ... Desde o início eu gostei muito e eu fui percebendo o jeito feminino, e eu fui querendo tanto ser uma menina, eu sentia esse desejo, esse sonho de ser mulher, sempre eu tive esse desejo feminino. (Transcrição, entrevista 2)

Pesquisador: "Pra gente começar a conversa, eu pergunto pra você: o que é ser surdo? Como é ser surdo?"

Artur: Aos 9 anos de idade aconteceu uma coisa comigo... é que meu primo teve uma relação comigo. Isso aconteceu aos 9 anos de idade. Eu não tive culpa, eu não sabia de nada, meus pais não me aconselharam, não me explicaram, eu dormia separado deles, eu dormia no chão, junto com meu primo. Daí, era muito cheio e acabou acontecendo que ele teve relação sexual comigo. Mas para mim isso foi normal, porque me deu essa condição e eu vejo que em muitos surdos a história da homossexualidade começa assim e ela vai se desenvolvendo com o tempo. (Transcrição, entrevista 3)

Lucas e Artur, desconsiderando a pergunta do pesquisador, começaram a relatar suas primeiras experiências sexuais com parceiros do mesmo sexo. Ambas ocorreram no ambiente familiar, sem a compreensão dos sujeitos sobre o que estava ocorrendo. Artur comentou: "Eu não tive culpa, eu não sabia de nada . . .". Lucas também ressaltou: “. . . eu tinha um primo que ficava junto comigo e que acabou tendo relação sexual comigo e eu fui criado junto com ele, mas eu não entendia nada daquilo".

Os relatos de Lucas e Artur apontam que ambos foram introduzidos à vida sexual ainda menores de idade, sem consentimento e sem convite. É possível afirmar, diante dos relatos, 
que os entrevistados viveram uma situação abusiva, pois não sabiam o que estava ocorrendo. $\mathrm{O}$ contexto, contudo, não foi conduzido pela violência física, mas simbólica. Lucas afirmou: " $E u$ fui entendendo... . . Eu gostei da relação homossexual. Então, eu também tinha relação com ele ...". Parece que Lucas, aos poucos, foi tendo prazer na relação sexual com o primo, estando de acordo com aquele tipo de envolvimento.

Entretanto, é importante salientar que Lucas e Artur viveram uma condição de vulnerabilidade social e sexual. Eles, em razão de sua condição orgânica, não tinham com quem falar sobre o que estavam vivenciando. Suas queixas não tinham pauta para elaboração, pois não podiam existir fora de uma plataforma de comunicação viável. Eles eram surdos em um ambiente de maioria ouvinte inacessível.

Mateus, diferente dos demais, ao narrar sua primeira experiência sexual, relata uma situação traumática de estupro vivenciada dentro de uma instituição de educação de surdos:

Mateus: Eu tinha 11 anos e o adulto surdo me estuprou no banheiro. Eu não entendi nada do que estava acontecendo, eu não sabia nada, eu na hora não entendi, pensei que era uma simples brincadeira, eu não tinha ideia do que estava acontecendo e o homem... ... Eu acredito que a partir dai eu fui contagiado pela homossexualidade, me tornando um homossexual. Por conta dessa experiência de estupro e a partir desse momento, eu acabei me acostumando a ter esse tipo de relação sexual. . . . Depois que eu sofri abuso, eu comecei a sentir vontade de ter essas relações, de continuar, porque eu já estava acostumado, pois começou aos 11 e foi até os 12 anos. (Transcrição, entrevista 1)

Ferreira (2008) argumenta que as pessoas com deficiência estão em risco de violência sexual por dois fatores: primeiro, por serem sujeitos invisíveis socialmente; e, segundo, pela consciência do agressor de que o risco de denúncia do abuso é praticamente inexistente, pois com frequência a pessoa com deficiência estará isolada e sem apoio (familiar e escolar).
No caso dos surdos, é importante ressaltar que a condição de incompatibilidade linguística com a comunidade ouvinte majoritária e a não aquisição da língua de sinais favorecem a emergência de contextos abusivos e geram situações complexas para a formação do surdo. Mateus declarou: “. . . e eu não entendi nada do que estava acontecendo, eu não sabia nada, eu na hora não entendi, pensei que era uma simples brincadeira".

A vulnerabilidade social e emocional contribui para o abuso sexual de pessoas com deficiência. Wanderer (2012) pesquisou 10 casos atendidos no contexto judicial de circunstâncias de violência contra pessoas com deficiência, no Distrito Federal. Dentre eles, o abuso sexual se fez presente em 5 denúncias. Os principais agressores eram pessoas que faziam parte da rede de apoio pessoal do sujeito (genitor, irmão, padrasto, vizinho etc). A autora chama a atenção para o fato de a escola e a família não fomentarem uma discussão eficaz sobre a sexualidade com esse público, ocasionando um desempoderamento para as vivências das práticas eróticas e afetivas e uma não agencialidade para as denúncias no caso de abusos.

Ainda sobre isso, Bisol (2008) apresenta um estudo realizado por Kvan (2004) com 1.150 adultos surdos na Noruega. Nesse estudo, constatou-se que crianças surdas podem ter de duas a três vezes mais chances de serem vítimas de abuso sexual. A questão da vulnerabilidade sexual também foi destacada na pesquisa de K. Ribeiro (2011), ao analisar a fala de mães de adolescentes surdas. A pesquisa revelou que as mães identificaram a surdez como um aspecto facilitador de violência sexual. Para elas, a falta de audição (e o problema de comunicação decorrente) dificulta a percepção da aproximação de um possível agressor e o pedido de ajuda.

Em suas narrativas, Lucas, Artur e Mateus estabeleceram ligações diretas entre o primeiro ato sexual e a homossexualidade. Bisol (2008) constata que os jovens, tanto surdos quanto ouvintes, tentam construir significados em torno da sexualidade, centrando-se principalmente no primeiro beijo e na primeira relação sexual: 
Poder pensar o peso que essas vivências têm para a compreensão de si e do outro, a necessidade de narrá-la indica a necessidade de organizá-la, em suma, de compreendê-la em sua imensa gama de sentimentos e conflitos (Bisol, 2008, p. 110).

Para os surdos pesquisados, as relações sexuais ocorridas na infância tardia são entendidas como um marco da sua condição homossexual, transversalizada pela experiência física e simbólica. Lucas afirma: "Desde o início, eu gostei muito e eu fui percebendo o jeito feminino, e eu fui querendo tanto ser uma menina, eu sentia esse desejo, esse sonho de ser mulher, sempre eu tive esse desejo feminino".

Ou seja, por meio dos relatos, podemos depreender que o ato sexual foi estabelecido como essencial no processo de construção da identidade sexual desses sujeitos, constituindo-se como marco subjetivo. Assim, para os surdos entrevistados, existe uma relação direta entre o primeiro ato sexual e a vivência (atual) da homossexualidade. Mateus comenta: "Eu acredito que a partir dai eu fui contagiado pela homossexualidade, me tornando um homossexual. Por conta dessa experiência de estupro e a partir desse momento, eu acabei me acostumando a ter esse tipo de relação sexual".

Nos fragmentos discursivos, percebemos que os entrevistados remeteram-se à sexualidade tendo como fundamento um conceito biologizante/naturalizante que a reduz ao ato sexual. Porém, conforme salienta Maia (2006), a sexualidade não se restringe ao sexo, sendo impossível dissociar o aspecto biológico das dimensões psicossocial e histórica. A sexualidade traz em sua essência uma amplitude de condutas humanas, que vão além da genitalidade; não deve, portanto, ser entendida exclusivamente como sinônimo de sexo, orgasmo ou órgãos sexuais, mas sim como uma dimensão ampla e cultural que abrange diferentes aspectos, como amor, relacionamentos afetivos e sexuais, prazer etc (Maia \& Aranha, 2005).

Os dados corroboram a constatação da pesquisa de Moukarzel (2003), que, ao analisar a fala de alunos com desenvolvimento peculiar sobre sexualidade, percebe que a sexualidade, para eles, é representada em sua dimensão biológica, tendo como foco principal a genitalidade. Nessa representação, não se estabelecem significações socioculturais, voltando-se a atenção para o corpo reprodutivo.

\section{Unidade de Análise 2: Estratégias de Enfrentamento do Duplo Preconceito}

Por meio da análise do material construído no campo, podemos identificar que o ocultamento é a estratégia prevalente de enfrentamento do preconceito referente à condição homossexual. Para os entrevistados, o estigma da surdez os coloca em um local de subalternidade marcado pelo preconceito e pela exclusão social. Soma-se a isso outro fator para sua possível desqualificação: sua orientação homossexual.

Dessa forma, a omissão da condição homossexual é elencada como um fator de proteção contra o duplo preconceito, fazendo com que os sujeitos assumam uma identidade heterossexual na esfera pública (como fator preponderante para sua aceitação dentro do seu grupo social). O segredo torna-se seu principal aliado, e a vigilância do corpo, algo corriqueiro. Tais elementos podem ser observados abaixo:

Mateus: "Eu sei que eu sou homossexual, eu tenho relações homossexuais, mas eu não gosto de ter um comportamento que denuncie isso, mas ligado às questões de trejeito, eu não gosto" (Transcrição, entrevista 1$)$.

Lucas: "Não, eu nunca encontrei com surdos homossexuais. Eu escondo que eu sou homossexual. . . . Os surdos não sabem que eu sou homossexual. Então, eu não convivo com eles. Eu finjo que sou hétero, entendeu?" (Transcrição, entrevista 2).

Ou ainda em outro trecho:

Lucas: Mas eu gostei muito de me relacionar com héteros [referindo-se aos homens que transam com homens mas não assumem uma identidade homossexual] se, só que eles não contam nada pra ninguém que eles se relacionam com a gente. Agora, homossexual fica contando pra todo mundo: "Eu sou gay, eu sou gay, eu sou gay”. Espalham 
para todo mundo... Eu não gosto disso. (Transcrição, entrevista 2)

Observa-se que os sujeitos da pesquisa escondem sua condição homossexual como forma de evitar um duplo preconceito. Os métodos mais relevantes apontados dizem respeito ao controle do corpo, evitando os trejeitos estabelecidos socialmente como femininos, bem como omissão da orientação sexual nos diversos ambientes em que os sujeitos transitam.

Artur aponta que muitas informações não chegam aos surdos de forma satisfatória, principalmente aquelas relacionadas à educação em sexualidade:

Artur: "Os surdos homossexuais sofrem muito preconceito, também, por essa falta de informação. Eles não vivem em paz. É uma vida muito dificil. Eu, por exemplo, tenho problema na minha familia até hoje por conta disso" (Transcrição, entrevista 3 ).

Por isso, torna-se urgente a necessidade de desenvolver programas de educação sexual para as pessoas com deficiência, que possam atender as suas necessidades informacionais com materiais didáticos adequados as suas peculiaridades. Percebe-se que seus conhecimentos sobre assuntos relacionados à sexualidade, no sentido amplo, são incorretos ou superficiais.

Beche (2005) alerta que, em geral, os surdos não recebem orientação sexual em casa, pois seus familiares utilizam a repressão como instrumento castrador de curiosidades e desejos. Devido a suas peculiaridades linguísticas, tais sujeitos possuem dificuldades em entender as informações veiculadas pelos meios de comunicação acerca dessa temática. Isso alerta para a necessidade de proporcionar espaços que prestem informações qualitativas para esse público, oportunizando ao deficiente um desenvolvimento maduro e saudável de sua sexualidade (Glat, 2004).

\section{Apontamentos Finais}

Durante muitos anos, a problemática da surdez ficou relegada à esfera patológica e aos processos de medicalização orientados pela incompletude decorrente da perda da audição e, consequente, do déficit de comunicação. A condição social do surdo é marcada pelo lugar da incapacidade, limitação e inferioridade. $\mathrm{O}$ não pertencimento à sociedade majoritária (ouvinte) trouxe estigmatização e exclusão, e a situação da surdez ficou, tradicionalmente, relegada à problemática da deficiência. Não diferente, $o$ homossexual, após sua invenção conceitual, foi marcado socialmente pela sua sexualidade incompleta, acidental e perversa - na pior das hipóteses, patológica, criminosa, imoral e destruidora da civilização (Borrillo, 2010).

Para os sujeitos surdos e homossexuais, ter-se-ia de inventar e executar uma série de ações visando à sua reintegração à normalidade: práticas oralistas e de deslegitimação linguística, para os surdos, e criminalização e ações médico-corretivas, para os homossexuais. De fato, em ambas as categorias, há sujeitos demarcados e reconhecidos socialmente como desviantes da norma, sendo seu destino a experiência de segregação e/ou reabilitação.

Em que pesem todas as transformações históricas correntes, os preconceitos e o cerceamento de direitos desses grupos persistem. Embora não sejam mais jogados ao mar ou lançados nas fogueiras, como no passado, continuam sendo duplamente silenciados pela sua situação orgânica (surdez) e pela expressão sexual considerada desviante (homossexualidade).

Os dados apresentados nesta pesquisa partem das narrativas de sujeitos surdos e homossexuais, que enfrentam cotidianamente as mais diversas situações de preconceito. Para eles, o momento (ponto de transição) definidor do reconhecimento da sua condição homossexual foi a primeira relação sexual, ocorrida na infância tardia, e a condição homossexual se define pela/na genitalidade e pelo/no sexo, pautada na relação corpórea. Em linhas gerais, pode-se sinalizar que os entrevistados identificam a sexualidade como algo relacionado à ação, não necessariamente vinculado à dimensão do afeto, da comunicação, da gratificação libidinosa ou da construção de vínculos. Há uma dificuldade em estabelecer associações diretas entre relações físicas e emocionais, o que pode estar ligado à problemática linguística e simbólica que circunscreve o surdo. 
Os surdos homossexuais vivem a condição de (dupla) subalternidade social, preferindo esconder a orientação sexual como forma de manter sua segurança e resguardar-se perante o olhar da comunidade surda. Há um temor confesso de que a sua homossexualidade seja descoberta, o que traz prejuízos sociais e psicológicos.

As questões levantadas ao longo deste trabalho apontam para a necessidade de ampliação das investigações sobre a temática da homossexualidade interseccionada à surdez, bem como sua interface com as políticas públicas de assistência e formação, tendo como pano de fundo a especificidade linguística dos sujeitos. É urgente o esforço conceitual e analítico para compreender a condição existencial ao longo do processo de desenvolvimento ontogenético de sujeitos surdos homossexuais.

\section{Referências}

Abreu, F. S. D., \& Silva, D. N. H. (2012, set.). Homossexualidade e surdez: Um estudo sobre as experiências sexuais em surdos. Trabalho apresentado na XXI Jornada de Educação Especial da Universidade Estadual Paulista Júlio de Mesquita Filho, Marília, SP, Brasil.

Amago, J. G. (2005). Re-invertase. La doble exclusión: vivir siendo homossexual y discapacitado. Madrid, Espanã: Comité Español de Representantes de Personas con Discapacidad.

Anderson, P., \& Kitchin, R. (2000). Disability, space and sexuality: Access to family planning services. Social Science \& Medicine, 51(8), 1163 1173. doi:10.1016/S0277-9536(00)00019-8

Bauman, Z. (1998). O mal-estar da pós-modernidade. Rio de Janeiro, RJ: Jorge Zahar.

Beche, R. C. E. (2005). A sexualidade do surdo: Retalhos silenciosos na constituição da sua identidade (Dissertação de mestrado em Educação, Universidade Federal de Santa Catarina, Florianópolis, SC, Brasil).

Bisol, C. A. (2008). Adolescer no contexto da surdez: Questões sobre a sexualidade (Tese de doutorado em Psicologia do Desenvolvimento, Universidade Federal do Rio Grande do Sul, Porto Alegre, RS, Brasil).

Borrillo, D. (2010). Homofobia: História e crítica de um preconceito. Belo Horizonte, MG: Autêntica.
Britzman, D. (1996, jan./jun.). O que é esta coisa chamada amor: Identidade homossexual, educação e currículo. Educação e Realidade, 21, 71-96.

Buzar, F. J. R. (2012). Interseccionalidade entre raça e surdez: A situação de surdos(as) negros(as) em São Luís - MA (Dissertação de mestrado em Educação, Universidade de Brasília, DF, Brasil).

Costa, P. R. (2011). "Surda mulher ser eu”: A construção das identidades do sujeito feminino (Dissertação de mestrado em Educação, Centro Universitário La Salle, Canoas, RS, Brasil).

Duarte, J. (2005). Entrevista em profundidade. In J. Duarte \& A. Barros (Eds.), Métodos e técnicas de pesquisa em comunicação (pp. 62-83). São Paulo, SP: Atlas.

Ferrari, A. (2005). Quem sou eu? Que lugar ocupo? Grupos gays, educação e a construção do sujeito homossexual (Tese de doutorado em Educação, Universidade Estadual de Campinas, SP, Brasil).

Ferreira, W. B. (2008). Vulnerabilidade à violência sexual no contexto da escola inclusiva: Reflexão sobre a invisibilidade da pessoa como deficiência. Revista Iberoamericana sobre Calidad, Eficacia y Cambio en Educación, 6(2), 120-136.

Foucault, M. (2006). História da sexualidade I: A vontade de saber. Rio de Janeiro, RJ: Graal.

Glat, R. (2004). Saúde sexual, deficiência e juventude em risco. Rio de Janeiro, RJ: Universidade do Estado do Rio de Janeiro.

Goffman, E. (1998). Estigma: Notas sobre a manipulação da identidade deteriorada (4. ed.). Rio de Janeiro, RJ: Guanabara.

House, L. (Produtora), \& Moorhouse, J. (Diretora). (1991). A Prova [Filme]. Melbourne, Austrália: House \& Moorhouse Films Pty.

Klein, M., \& Formozo, D. (2007). Gênero e surdez. Reflexão e Ação, 15, 100-112.

Kvan, M. H. (2004). Sexual abuse of deaf children. A retrospective analysis of the prevalence and characteristics of childhood sexual abuse among deaf adults in Norway. Child Abuse \& Neglect, 28(3), 241-251. doi:10.1016/j.chiabu.2003.09.017

Lebedeff, T. B. (1993). Percepção de jovens surdos sobre sua sexualidade (Dissertação de mestrado em Educação, Universidade Estadual do Rio de Janeiro, RJ, Brasil). 
London, M. (Produtor), \& Bezucha, T. (Diretor \& Roteirista). (2005). Tudo em família [Filme]. Los Angeles, CA: 20th Century Fox Home Entertainment.

Louro, G. L. (1997). Gênero, sexualidade e educação: Uma perspectiva pós-estruturalista. Petrópolis, RJ: Vozes.

Louro, G. L. (2009). Heteronormatividade e homofobia. In R. D. Junqueira, Diversidade sexual na educação: Problematizações sobre homofobia nas escolas (pp. 85-94). Brasília, DF: Ministério da Educação, Secretaria de Educação Continuada, Alfabetização e Diversidade.

Lopes, L. P. M. (2008). Sexualidade em sala de aula: Discurso, desejo e teoria queer. In A. F. Moreira \& V. M. Candau (Eds.), Multiculturalismo: Diferenças culturais e práticas pedagógicas (pp. 125-148). Petrópolis, RJ: Vozes.

Luczak, R. (1993). Eyes of desire: A dealf gay \& lesbian. Boston, MA: Alyson Books.

Luczak, R. (2013). Notes of a deaf gay writer: 20 years later. Boston, MA: Smashword.

Madureira, A. F. A. (2000). A construção das identidades sexuais não-hegemônicas: Gênero, linguagem e constituição da subjetividade (Dissertação de mestrado em Psicologia do Desenvolvimento, Universidade de Brasília, DF, Brasil).

Madureira, A. F. A., \& Branco, Â. U. (2001). A pesquisa qualitativa em Psicologia do Desenvolvimento: Questões epistemológicas e implicações metodológicas. Temas em Psicologia, 9(1), 6375.

Maia, A. C. B. (2006). Sexualidade e deficiência. São Paulo, SP: Editora da Universidade Estadual Paulista Júlio de Mesquita Filho.

Maia, A. C. B. (2009a). Deficiência mental e gênero: A heronormatividade como preconceito. In P. R. M. Ribeiro, Gênero, sexualidade e educação sexual em debate (pp. 11-23). São Paulo, SP: Cultura Acadêmica.

Maia, A. C. B. (2009b). Sexualidade, deficiência e gênero: Reflexões sobre padrões definidores de normalidade. In R. D. Junqueira (Ed.), Diversidade sexual na educação: Problematizações sobre homofobia nas escolas (pp. 265-291). Brasília, DF: Ministério da Educação, Secretaria de Educação, Continuada, Alfabetização e Diversidade.
Maia, A. C. B. (2010). Sociedade inclusiva e sexualidade: Reflexões sobre deficiência e a diversidade sexual. In E. G. Mendes \& M. A. Almeida (Eds.), Das margens ao centro: Perspectivas para as politicas e praticas educacionais no contexto da educação especial inclusiva (pp. 433-442). Araraquara, SP: Junqueira e Marin.

Maia, A. C. B., \& Aranha, M. S. F. (2005). Relatos de professores sobre manifestações sexuais de alunos com deficiência no contexto escolar. Interação em Psicologia, 9(1), 103-116. doi:10.5380/ psi.v9i1.3290

Maia, A. C. B., \& Ribeiro, P. R. M. (2010, maio/ ago.). Desfazendo mitos para minimizar o preconceito sobre a sexualidade de pessoas com deficiências. Revista Brasileira de Educação Especial, 16(2), 159-176. doi:10.1590/S141365382010000200002

Moreira, S. Z. (1998). A mulher surda e suas relações de gênero e sexualidade. In C. Skliar (Ed.), A surdez: Um olhar sobre as diferenças (pp. 95103). Porto Alegre, RS: Mediação.

Moukarzel, M. G. M. (2003). Sexualidade e deficiência: Superando estigmas em busca da emancipação (Dissertação de mestrado em Educação, Universidade Estadual de Campinas, SP, Brasil).

Nunan, A. (2003). Homossexualidade: Do preconceito aos padrões de consumo. Rio de Janeiro, RJ: Caravansarai.

Paula, A. R., Regen, M., \& Lopes, P. (2005). Sexualidade e deficiência: Rompendo o silêncio. São Paulo, SP: Expressão e Arte.

Ribeiro, D. (Produtor, Diretor, \& Roteirista). (2014). Hoje eu quero voltar sozinho [Filme]. São Paulo, SP: Lacuna Filmes.

Ribeiro, K. (2011). Sexualidade e gênero: Estudo das relações afetivas de jovens surdas de uma escola municipal de educação especial de São Paulo (Tese de doutorado em Educação, Universidade de São Paulo, SP, Brasil).

Sànchez, F. L. (2013). Sexo y afecto em personas com discapacidad. Madrid, España: Biblioteca Nova.

Skliar, C. (2010). Os estudos surdos em educação: Problematizando a normalidade. In C. Skliar (Ed.), A surdez: Um olhar sobre as diferenças (4. ed., pp. 7-32). Porto Alegre, RS: Mediação.

Silva, J. G. (2011). Desejos e afetividades que não querem calar: O grupo LGBT surdo de Pernambuco [Monografia de Especialização]. Olinda, PE: Fundação de Ensino Superior de Olinda. 
Souza, T. Y., Branco, A. M., \& Lopes de Oliveira, M. C. S. (2008, jul./dez.). Pesquisa qualitativa e desenvolvimento humano: Aspectos históricos e tendências atuais. Fractal, Revista de Psicologia, 20(2), 357-376. doi:10.1590/S198402922008000200004

Vigotski, L. S. (1997). Fundamentos de defectologia: Vol. 5. Obras escogidas. Madrid, España: Visor.

Wanderer, A. (2012). Violência intrafamiliar contra pessoas com deficiencia: Discutindo vulnerabilidade, exclusão social e as contribuições da Psicologia (Dissertação de mestrado em Psicologia do Desenvolvimento, Universidade de Brasília, DF, Brasil).
Weeks, J. (2007). O corpo e a sexualidade. In G. L. Louro (Ed.), O corpo educado: Pedagogias da sexualidade (2. ed., pp. 37-82). Belo Horizonte, MG: Autêntica.
Recebido: 03/06/2013

$1^{a}$ revisão: 22/05/2014

$2^{a}$ revisão: $18 / 07 / 2014$

Aceite final: 21/07/2014 